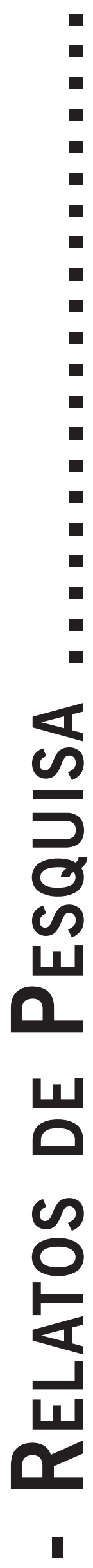




\title{
"DUAS FACES DA MESMA MOEDA": VIVÊNCIA DOS PSICÓLOGOS QUE ATUAM NA REDE DE ATENÇÃO PSICOSSOCIAL
}

\author{
Two Sides of the Same Coin: The Experience of Psychologists in \\ Psychosocial Care Network \\ Dos Caras de la Misma Moneda: La Experiéncia de los Psicólogos en la \\ Red de Atención Psicosocial
}

Camila MuHL

ADRIANO FurTado Holanda

\begin{abstract}
Resumo: A partir da instituição da Lei 10.216, da Portaria 3.088 e com a implementação da Rede de Atenção Psicossocial, a atuação em saúde mental pública no Brasil passa por grandes transformações, as quais os profissionais de saúde precisam se adaptar. O objetivo deste artigo é pesquisar e compreender as vivências dos psicólogos que atuam em saúde mental pública têm no cotidiano do seu serviço. Para tal, optou-se por um estudo fenomenológico onde foi realizada entrevista aberta com seis psicólogos que atuavam na Rede de Atenção Psicossocial. Como resultado, chegou-se ao entendimento de que esta é uma experiência bastante conflituosa, em que a vivência do psicólogo fica presa em dualidades: satisfação versus frustração, identificação com a área de saúde mental versus designação aleatória para o cargo, legislação versus realidade do serviço, e vida profissional versus vida pessoal. Palavras-chave: Experiência, Atuação do Psicólogo, Saúde Mental, Rede de Atenção Psicossocial.
\end{abstract}

Abstract: From the enactment of Law 10.216, of Ordinance 3.088 and the implementation of Psychosocial Care Network, the public mental health work in Brazil goes through great changes, which health professionals must adapt. The purpose of this article is to research and understand the experiences of psychologists working in public mental health has on everyday of your service. With this aim, we opted for a phenomenological study which was conducted open interviews with three psychologists who worked on Psychosocial Care Network. As a result, came to the understanding that this is a rather conflicting experience, in which the experience of the psychologist gets trapped in dualities: satisfaction versus frustration, identification with the area of mental health versus random assignment to the office, law versus reality service, and professional life versus personal life.

Keywords: Experience, the Psychologist, Mental Health, Psychosocial Care Network.

Resumen: Desde la promulgación de la Ley 10.216, de la Ordenanza de 3.088 y la implementación de la Red de Atención Psicosocial, el público el trabajo de salud mental en Brasil pasa por grandes cambios, que los profesionales de salud deben adaptarse. El propósito de este artículo es investigar y comprender las experiencias de los psicólogos que trabajan en salud mental pública tiene en todos los días de su servicio. Con este fin, se optó por un estudio fenomenológico que se realizó entrevistas abiertas con tres psicólogos que trabajaron en la Red de Atención Psicosocial. Como resultado, llegó a la comprensión de que esta es una experiencia bastante conflictiva, en la que la experiencia del psicólogo queda atrapada en dualidades: la satisfacción frente a la frustración, la identificación con el área de la salud mental en comparación con asignación aleatoria a la oficina, la ley y la realidad servicio, y la vida profesional frente a la vida personal.

Palabras-clave: Experiencia, el Psicólogo, de Salud Mental, de la Red de Atención Psicosocial.

\section{Introdução}

Este trabalho tem como objetivo compreender as vivências que os psicólogos que atuam na saúde mental pública têm no seu cotidiano. Tendo em vista que apenas a legislação e as diretrizes oficiais do Sistema Único de Saúde (SUS) não determinam de todo o que ocorre dentro do serviço, investigamos quais as experiências e situações significativas que os profissionais da psicologia estão enfrentando junto à Rede de Atenção Psicossocial (RAPS).

A partir de uma perspectiva fenomenológica, entrevistamos seis psicólogos que atuam em serviços de referência de saúde mental na 1ª Regional de Saúde do Paraná, a qual abriga os municípios do litoral paranaense. O que encontramos nas suas respostas foram experiências muito conflituosas, em que sentimentos opostos, como satisfação e frustração, parecem sempre andar juntos.

Para apresentar os dados obtidos em nossa pesquisa, primeiramente discutimos o conceito de vivência, a partir da perspectiva fenomenológica apresentada por Edmund Husserl e Wilhelm Dilthey. Em seguida, são caracterizados o método e o perfil dos nossos entrevistados, para depois, apresentarmos as dualidades presentes na prática dos psicólogos que atuam em saúde mental pública. 


\section{Buscando a compreensão da vivência}

“[...] a tarefa de compreender seria impossível se as manifestações vitais nos fossem inteiramente estranhas e seria desnecessária se não existisse nas manifestações vitais algo estranho.” Wilhelm Dilthey

Num primeiro momento a opção por centrar na vivência a coleta de dados de uma pesquisa pode parecer um pouco singular, visto que essa não é uma prática corrente, pelo menos não intencionalmente. Entretanto, a fenomenalidade da vivência é fértil de conteúdos e a sua compreensão é a busca desse artigo, mas para chegar a esse objetivo é preciso desvelar os sentidos desse conceito.

Sob a tutela do pensamento husserliano e diltheyano ${ }^{1}$, identificamos no conceito de vivência a oportunidade de quebrar os dualismos que permeiam as teorias científicas. A vivência é o elo de ligação entre o geral e o individual, entre o universal e o singular, entre o objetivo e o subjetivo, entre a natureza e a cultura e de alguma forma ela consegue capturar, ainda que por um breve instante, a relação parte-todo, é a figura e o fundo vistos simultaneamente. Mas que configuração é essa que a vivência assume e que a torna capaz de ligar esses termos até então opostos?

O termo vivência é um neologismo criado por Ortega y Gasset (1913/2011) a partir da tradução do vocábulo alemão Erlebnis, e pode ser entendido como um sinônimo de experiência vivida. Dilthey (1894/2008, p. 128) descreve a vivência como "a atuante conexão viva no seio da vida anímica e do mundo histórico”, assim sendo, um símbolo verdadeiro da experiência plena e não mutilada da realidade, por isso tão central para as pesquisas em ciências do espírito. Pensando então a vivência como a experiência vivida que forma um fluxo, Holanda (2003, p. 172) assinala que a vivência inclui os "próprios conteúdos reais, imediatos, da consciência de cada um, os dados perceptivos, representativos e ideativos, as emoções, sentimentos, desejos, decisões, as experiências de êxtase, as dúvidas e ímpetos". Portanto, uma variedade de situações que acabam por se entrelaçar e formar uma corrente de vivências.

Dilthey (1970/2010) defende que é no elemento vivencial que está contido todo o valor da vida: é ele que traz significação, valor e finalidade para as ações. Peres (2014) esmiúça melhor essa relação: para Dilthey, cada vivência é parte de um todo estruturado que se chama vida, e cada

\footnotetext{
Husserl e Dilthey convergem na ideia de que é necessário fundar um novo projeto de Psicologia, que não mais siga as regras e métodos das ciências naturais, tão comum na virada do século XIX para XX, época em que esses autores estão produzindo. É nesse contexto, que a noção de vivência aparece como o fundamento dessa nova Psicologia, agora uma ciência do espírito, tal seja, uma ciência humana.
}

uma dessas vivências está imersa num tempo histórico e cultural específicos, esses elementos dão à vivência um horizonte de sentido - significado - que deve ser analisado pelo pesquisador a luz do todo. Ainda sobre as diversas ramificações do conceito de vivência em Dilthey, vejamos a contribuição de Amaral (2004):

Poderíamos começar argumentando que vivência é a própria vida reduzida nas suas proporções mais diminutas e ao mesmo tempo mais fidedignamente representativas do modelo em tamanho original. Poderíamos também lembrar as palavras de Dilthey em seu Tratado da Realidade (1890), salientando que a vivência, ao encerrar a própria vida é, como esta, "continuamente sua própria prova”. Isto significa dizer que ela constitui a zona limite do conhecimento, isto é, o último fundamento do conhecimento. É como se, ao conter a vitalidade em toda a sua força de expressão, estabelecesse o marco divisório para além do qual o pensamento não tivesse acesso. $\mathrm{Ou}$, ainda de outro modo, a vivência constitui o próprio critério vivo responsável pela triagem dos fatos da consciência, já que para o autor estes são dados em nossas vivências (Amaral, 2004, p. 52).

A partir desta citação queremos destacar duas perspectivas que nos ajudam a fundamentar a vivência como fonte de informações para a pesquisa. A primeira delas diz respeito à vivência conter numa fração reduzida todas as características da vida, este entendimento permite encontrar em recortes e relatos, informações que dizem respeito ao todo, como, por exemplo, a relação experienciada entre psicoterapeuta e cliente em terapia permite compreender a forma como o cliente mantém seus relacionamentos para fora da sessão ou como em uma entrevista onde um pequeno fragmento pode conter os sentidos da fala, o que nos leva ao segundo ponto de destaque. Se a vivência realiza a triagem dos fatos de consciência, é através dela que eles são significados e valorados. Exemplificando, numa interação como uma entrevista, a partir das perguntas feitas, alguns fatos são destacados e escolhidos pelo entrevistado para aprofundar, isso ocorre justamente porque estes fatos são significativos para o entrevistado, retratos reais da sua experiência, e é sobre eles que devemos nos debruçar.

Nesse sentido, nosso argumento, de inspiração diltheyana, é o de que não podemos estudar Religião, por exemplo, sem falar da vivência religiosa, como também não poderíamos estudar Arte sem falar da vivência que certas pinturas nos provocam. É com a atenção direcionada para a vivência que nós pesquisadores conseguimos colocar conceitos até então abstratos em relação com o mundo. 


\section{Método}

Fazer pesquisa em ciências humanas é caminhar em busca de significados. Adriano Furtado Holanda

Para pesquisar as vivências dos psicólogos no seu cotidiano de trabalho em saúde mental pública na $1^{\mathrm{a}}$ Regional de Saúde do Paraná fizemos uso de um método qualitativo de cunho fenomenológico. O método fenomenológico busca a descrição das experiências vividas pelos sujeitos pesquisados sobre um determinado fenômeno, dessa forma, é um método privilegiado para o estudo das vivências e dos seus significados (Andrade \& Holanda, 2010). A fenomenologia se preocupa com a base real (ou seja, empírica) da experiência consciente, com a relação entre sujeito e objeto, consciência e experiência, e com o mundo vivido. O interesse das investigações fenomenológicas é justamente esse mundo vivido e nesse contexto a entrevista aparece como uma comunicação que não se limita a conhecer a vivência particular de uma determinada pessoa em um determinado lugar, mas sim deseja conhecer como diferentes pessoas experienciam uma certa condição que é comum a elas (Gomes, 1997).

A condição por nós investigada foi a de ser psicólogo da rede de atenção à saúde mental pública. Para chegarmos até os nossos colaboradores, contamos com a parceria do Comitê Intersetorial de Saúde Mental da referida Regional, que nos repassou informações acerca da rede e nos indicou os serviços de saúde mental de referência em cada município. Como colaboradores tivemos seis psicólogos que atuam nos serviços de referência em saúde mental da Rede de Atenção Psicossocial da $1^{\text {a }}$ Regional de Saúde do Paraná que compreende os municípios do litoral do Estado: Antonina, Guaraqueçaba, Guaratuba, Matinhos, Morretes, Paranaguá e Pontal do Paraná. A coleta dos dados de pesquisa foi feita por meio de entrevista aberta. As entrevistas foram realizadas no próprio local de trabalho dos psicólogos, sendo o áudio gravado e posteriormente transcrito para análise.

Dos sete municípios do litoral paranaense, dois deles não possuíam serviço de referência em saúde mental, e num terceiro município o serviço de referência - um hospital - não possuía em seu quadro de funcionários um psicólogo. Dessa forma, as entrevistas foram realizadas em quatro municípios, onde encontramos oito psicólogos atuando em Centros de Atenção Psicossocial, mas dois deles foram excluídos da pesquisa por não atenderem ao critério de estarem atuando no serviço a pelo menos três meses.

Como procedimento metodológico para a pesquisa da experiência, seguimos as etapas conforme propostas por Gomes (1997), a saber: 1) descrição fenomenológica, 2) redução fenomenológica e 3) interpretação fenomenológica. Na primeira etapa foi realizada uma descrição densa do objeto de estudo - a vivência dos psicólogos que atuam em saúde mental pública - a partir dos dados empíricos colhidos junto às entrevistas. Na segunda etapa, o material foi organizado em unidades compreensivas, e então foi realizada a interpretação do material pelos pesquisadores. Essas etapas foram repetidas tantas vezes quanto necessário para se chegar à essência do objeto estudado.

Todos os preceitos éticos foram seguidos no desenvolvimento deste trabalho, assim como foram colhidos os Termos de Consentimento Livre e Esclarecido. Essa pesquisa é integrante do projeto de pesquisa intitulado "Atenção em Saúde Mental no Paraná: Serviços, Profissionais e Dispositivos de Atenção na Regional de Saúde do Litoral” que foi aprovado pelo Comitê de Ética em Pesquisa da UFPR (sob o protocolo 25380113.6.0000.0102) e também pelo Comitê Intersetorial de Saúde Mental, órgão sob o qual a pesquisa foi desenvolvida.

\section{Os psicólogos do litoral do Paraná}

Pois o psíquico não é aparência empírica, é vivência. Edmund Husserl

Para compreendemos a vivência de uma pessoa é necessário compreender também o seu lugar de fala. Em virtude disso, para compreender as vivências dos psicólogos da Rede de Atenção Psicossocial no Litoral do Paraná consideramos importante traçar o perfil, caracterizar os nossos entrevistados. Entretanto, faremos isso apenas na medida em que não será possível identificá-los.

Os psicólogos entrevistados têm idade entre 27 e 44 anos, todos trabalham em Centros de Atenção Psicossocial no Litoral do Paraná, em diferentes cidades, ocupando o cargo de psicólogo do serviço, e em três casos ocupam também o cargo de coordenador do serviço. Foram quatro CAPS visitados no Litoral e, desses, três tinham psicólogos ocupando o cargo de coordenador ${ }^{2}$. O tempo de atuação no serviço de saúde mental em que trabalham atualmente varia de 4 a 36 meses, e muitos deles atuam no referido serviço desde a sua abertura. Em apenas um caso, essa é a primeira experiência de atuação em saúde mental, sendo que a experiência dos outros psicólogos nessa área varia de 21 a 84 meses. Quanto aos locais prévios de atuação em saúde mental foram citados: ambulatório de saúde mental, Centro de Atenção Psicossocial, Unidade Básica de Saúde, Atenção Básica (capacitação de profissionais) e consultório particular.

De um modo geral, podemos falar que o psicólogo que atua no litoral do Paraná na Rede de Atenção Psicossocial é adulto-jovem, tem experiência prévia com atuação em saúde mental e atua há pouco tempo no serviço atual (em cinco casos, menos de 18 meses).

\footnotetext{
No quarto CAPS, o cargo de coordenador do serviço era ocupado por um profissional do Serviço Social.
} 


\section{As vicissitudes de ser-psicólogo na rede de atenção psicossocial}

O ser humano faz do ser humano uma experiência contraditória.

Michel Foucault

Durante as entrevistas com os psicólogos, e depois, nos aprofundando na leitura e compreensão da transcrição das mesmas, destacou-se a presença de sentimentos opostos, mas esses sentimentos não eram opostos entre um psicólogo e outro, e sim, se encontravam presentes no mesmo profissional. Um mesmo entrevistado relatava satisfação e, no momento seguinte, falava de frustração, seguia dizendo que estava realizado com a vida profissional e depois falava que a mesma atrapalhava sua vida pessoal, e essas oposições foram se repetindo em todas as entrevistas. Optamos por nomear essas oposições como dualidades e através delas apresentamos nossos resultados. A escolha pelo termo dualidade, ao invés de dualismo, se dá por entendemos que essas posições não são distintas umas das outras, mas que estão em relação, existindo um fluxo entre elas. Como uma ilustração, podemos pensar em uma moeda, que de um lado é cara e de outro é coroa, e exatamente por isso se constitui como moeda: a existência de apenas um dos lados sem o outro, impede a significação deste como uma moeda, a moeda só existe a partir da sua dualidade.

Entretanto, não podemos nos esquecer que não é possível ver todos os lados da moeda com apenas um olhar, o fenômeno moeda nos é dado por perspectivas ou perfis, e cada um desses perfis nos dá a noção da moeda toda (Husserl 1913/2006). Estas elaborações nos levam para o significado do fenômeno para a fenomenologia: é aquilo que aparece para uma consciência. Portanto, o fenômeno não é o objeto em si, nem está na consciência, e sim está diante de, é a apresentação de algo para a consciência. Assim sendo, não podemos separar o fenômeno da experiência concreta das pessoas no mundo, pois é só assim que eles se apresentam a consciência (Husserl 1913/2006, Holanda, 2014).

Ainda como forma de tensionar o exemplo da moeda, Kelkel e Schérer (1954) identificam que as várias perspectivas ou perfis que a mim se apresentam são o fenômeno moeda: cor, textura, aparência, número ou figura. A coisa percepcionada é esse complexo de aparências que eu vivencio, não existindo uma coisa real, verdadeira, em si, por detrás de todas essas perspectivas. O fenômeno, portanto "não é um dado absoluto - e incognoscível, ou seja, que não se pode conhecer - nem um 'em si' (inacessível). A fenomenologia lida com experiência, com vivências, e fenômeno aqui é sempre um correlato dessa experiência” (Holanda, 2014, p. 49). Fazendo a ligação da ideia de fenômeno enquanto aquilo que aparece a consciência e as nossas entrevistas, a seguir apresentaremos os vários perfis ou perspectivas apresentadas pelos nossos entrevistados sobre ser psicólogo na rede de atenção à saúde mental, tendo como ponto de partida para a discussão as dualidades por nós encontradas: satisfação versus frustração, identificação com a área de saúde mental versus designação aleatória para o cargo, legislação versus realidade do serviço, e vida profissional versus vida pessoal.

\subsection{Satisfação versus frustração}

A primeira das dualidades que iremos apresentar e discutir são as vivências de satisfação e frustração, que parecem estar interligadas no que diz respeito ao trabalho com saúde mental no setor público. Os entrevistados relatavam os dois sentimentos em uma mesma frase, ou quando questionados sobre um, acabavam discorrendo sobre o outro, como podemos ver nos trechos abaixo:

O que realiza é trabalhar com a Saúde Mental, eu acho assim que os resultados que a gente consegue por mais que sejam lentos e às vezes frustrantes, porque tu vê às vezes o retorno do paciente, às vezes você consegue um resultado bom e daqui dois, três anos ele retorna (PC4). É penoso, porque muitas vezes a gente tem que brigar com o familiar com questão de medicação, que eles têm dificuldade de dar medicação, mas é gratificante (PC6).

Olhando para cada um desses sentimentos individualmente, podemos perceber que a satisfação está ligada a duas frentes principais: a melhora do usuário de saúde mental e o trabalho em equipe. A preocupação com o usuário do serviço e o empenho na melhora da sua condição aparece nos relatos como a principal motivação para o trabalho desses profissionais:

Eu chego a noite em casa com a sensação de dever cumprido. Eu percebo que os meus pacientes melhoram sim, quando é feito da melhor maneira possível considerando todas as dificuldades, então eu vejo que sim, que a psicoterapia ela funciona (PC2).

Um paciente aqui, chegou aqui e não olhava na cara de ninguém, não ria, e hoje o cara está aqui dando aula de informática para os pacientes, se sentindo gente, se sentindo útil, se sentindo produtivo a sociedade, isso é gratificante (PC4).

A satisfação que os psicólogos sentem em relação à melhora das pessoas que frequentam os seus serviços parece estar relacionada também com a capacidade de empatia desses profissionais com a situação de vida das pessoas com transtornos mentais. Ao se colocarem no lugar dos usuários, os profissionais conseguem perceber mais profundamente a diferença que o serviço e a sua atuação fazem na vida dessas pessoas. Vejamos o relato a seguir: 
A nossa preocupação é o nosso paciente, então, às vezes a gente briga por causa deles né, porque eles já são fragilizados então a gente procura sempre proporcionar para eles o que eles têm de direito e o que eles merecem que é dignidade, que é a garantia de direito deles e principalmente, que é o nosso compromisso, que é a qualidade na prestação dos serviços ao usuário (PC2).

Além do trato com os usuários, o trabalho em equipe também aparece como uma grande fonte de satisfação no trabalho em saúde mental, gerando apoio para os psicólogos. Vejamos os relatos sobre a importância do trabalho em equipe na Rede de Atenção Psicossocial:

É claro que eu não posso te dizer que a gente não discute, que não tem briga, principalmente nas reuniões, mas de uma maneira geral o trabalho funciona, como eu disse antes, eu me sinto muito bem trabalhando na equipe, porque a gente tem uma equipe muito boa, a gente está todo mundo empenhado, todo mundo querendo fazer o melhor (PC1).

[...] e essa coisa de trabalhar em equipe, eu adoro trabalhar em equipe, eu acho muito legal essa inter-relação essa troca com outros setores acho que isso me motiva muito (PC4).

A equipe se mostra importante em vários momentos do cotidiano desses profissionais: na tomada de decisão sobre os usuários, quando os psicólogos podem consultar os colegas (ou serem consultados) em algum atendimento complexo, nas reuniões de equipe onde são definidos os rumos do serviço, por exemplo. Mas a equipe também se mostra fundamental para cuidar do cuidador, onde os psicólogos procuram o cuidado dos colegas nos momentos de tensão, onde a sua própria saúde mental parece estar ameaçada.

Quanto à frustração, ela advém das dificuldades encontradas pelos psicólogos para desenvolver o seu trabalho com excelência, ou seja, fatores externos à atuação profissional em si, tais como: falta de estrutura no serviço para atender os usuários, falta de profissionais, falta de apoio da gestão municipal, falta de apoio dos familiares ao tratamento, não compreensão dos objetivos dos serviços de saúde mental, sendo que esta pode ser por parte dos usuários, gestores, familiares ou dos próprios profissionais. Vejamos abaixo dois relatos sobre essa última dificuldade, um em relação aos usuários e outro em relação aos profissionais:

Para mim é desafiador sempre, às vezes o próprio usuário nos cobra de uma forma completamente incoerente (PC3).

Eu acho que qualquer lugar você estuda os ideais de um serviço né e você encontra barreiras pelos modelos anteriores que não deixam de existir nem dentro de você e que você vai se deparando a cada tempo, e se você tem essa visão, você ainda tenta romper e dar um próximo passo no seu objetivo que você conhece bem qual é, mas a gente observa assim, aquelas velhas coisas da instituição, como que eu posso dizer, velhos modos, velhos costumes, hábitos de infantilizar o paciente, de muita ordem (PC5).

No segundo relato, fica clara a insatisfação do psicólogo entrevistado em relação aos profissionais que trabalham na área de saúde mental e que ainda operam pela lógica manicomial. Como estão ocorrendo alterações nessa área no Brasil, desde a Lei 10.216 (Brasil, 2011), até a recente Portaria 3.088 (Ministério da Saúde, 2011), parece não estar claro aos profissionais qual é a lógica pela qual devem operar, então surgem essas situações de discordância sobre a forma de ação mais apropriada entre os profissionais do serviço, mas também com os usuários que, por exemplo, podem solicitar internação psiquiátrica mesmo quando os profissionais não a consideram adequada.

Em um estudo anterior (Muhl, 2015), já foram demonstradas algumas dessas frustrações que os profissionais enfrentam, em relação às particularidades deste território específico, como o abandono dos usuários na época da temporada, e as dificuldades relacionadas com os problemas de comunicação com a gestão e com os outros serviços da RAPS. Ainda nesse texto, relataremos mais algumas dessas frustrações que dizem respeito à realidade do serviço. Como podemos perceber, as frustrações são muitas e advém de diversos fatores, o que faz com que os psicólogos entrevistados precisem atuar em várias frentes para tentar contornar esses problemas que aparecem cotidianamente nos seus serviços.

Problematizando todas as falas acima apresentadas notamos que um mesmo objeto pode ser uma potencial satisfação ou frustração. Em relação ao usuário do serviço, por exemplo, a melhora deste provoca satisfação e o abandono ou mesmo um retrocesso no atendimento causa frustração. Assim, torna-se possível observar o fluxo que é criado entre essas vivências, tal seja, a dualidade de sentimentos relacionadas com cada um dos aspectos cotidianos desses psicólogos em seu fazer profissional.

\subsection{Identificação com a área de saúde mental versus designação aleatória para o cargo}

Ao pesquisarmos o que levou os psicólogos entrevistados a atuar na Rede de Atenção Psicossocial encontramos duas situações bastante distintas: em alguns casos, os profissionais já se identificavam com a atuação em saúde mental e por isso procuraram uma colocação nessa área, em outros casos, não há essa identificação com a área de saúde mental, e os profissionais acabaram sendo designados para atuar na RAPS. Em relação aos psicólogos que procuraram intencionalmente trabalhar com saúde mental, essa identificação já começa a aparecer na época de 
graduação e acaba por influenciar toda a formação desses profissionais, sendo decisiva para as primeiras experiências profissionais. Vejamos alguns relatos:

Na verdade, para mim está sendo um sonho realizado, porque eu sempre gostei da área de saúde mental, desde a graduação. [...] minha graduação inteira foi muito norteada pela área de saúde mental, e sempre quis trabalhar num CAPS, por ser muito simpatizante dos movimentos da Antipsiquiatria, da luta antimanicomial, da mudança de paradigma do modelo hospitalocêntrico para os centros substitutivos, então, eu sempre fui muito apaixonado por essa área, então eu trabalho com bastante gosto (PC2).

Eu acho o máximo né, porque eu acredito muito no CAPS. Na faculdade, eu fiz estágio num CAPS infantil e me apaixonei (PC5).

Em alguns casos a identificação se dá com uma teoria associada ao campo da saúde mental, aqui entendida como um modelo de compreender a saúde e a doença mental específico, nesse caso a Antipsiquiatria ${ }^{3}$ citada pelo entrevistado, mas existem outras tantas teorias e modelos em saúde mental que acabam por orientar modos diferentes de cuidado às pessoas com transtornos mentais. Em outros casos a identificação ocorreu pela prática, pelo fazer da psicologia em saúde mental. Apesar de a identificação com a área de saúde mental ter se dado por razões distintas, os psicólogos deste primeiro grupo tiveram um papel ativo na busca por um emprego que fosse na sua área de atuação de preferência.

Entre os profissionais que não tinham identificação com a área de saúde mental e acabaram sendo designados para esses cargos, temos o caso em que o psicólogo foi aprovado em concurso público e somente depois soube onde seria seu local de atuação e também temos o caso em que o profissional trabalhava em outra área do setor público e depois foi deslocado para a atenção à saúde mental. Nos relatos abaixo podemos observar como os psicólogos se posicionam sobre essa questão:

[...] quando eu me formei eu fui diretamente para trabalhar em empresa, sempre trabalhei em RH, adorava, amava RH, nunca me imaginei trabalhando em Saúde Pública muito menos clínica, era uma coisa que para mim era meio distante [...] fiz o concurso por acaso, passei, aí falei: "vou experimentar" (PC4).

Olha, eu sempre tive bastante dificuldade com saúde mental, não era uma das áreas que eu mais gostava (PC6).

Entretanto, essa não-identificação com a atuação em saúde mental não é definitiva. Os psicólogos entrevista-

\footnotetext{
3 Movimento que se opõe a psiquiatria tradicional, as internações e a segregação causada pelo diagnóstico de um transtorno mental. Tem entre seus principais autores David Cooper e Ronald Laing.
}

dos relataram que depois de começar o trabalho na RAPS as suas impressões sobre esse trabalho se modificaram, e hoje se encontram satisfeitos com o seu local de atuação. Um dos entrevistados inclusive chega a afirmar que agora "ama" o que faz.

[...] sei que assim, dois meses eu já estava familiarizada [com a saúde pública], já estava começando a gostar e já nem lembrava que tinha trabalhado em empresa. Amei. Amei de primeira (PC4).

[...] agora a última vez a gente foi para um congresso em Curitiba, e eu falei "Nossa, parece que a gente não se dava tanto, mas agora a gente se entende melhor eu e a psicologia da saúde mental" (PC6).

Para além da identificação ou não com a área de saúde mental, existe também nos profissionais uma satisfação em poder trabalhar naquilo em que se formaram: a psicologia.

Para mim é um prazer trabalhar como psicóloga, em qualquer lugar eu acho que vou gostar muito, poder trabalhar numa coisa que eu acredito (PC5).

Apesar dessa realização profissional que os psicólogos entrevistados alegam ter com a sua área de formação, essa não é acrítica. Os profissionais refletem sobre o seu cotidiano e as dificuldades que enfrentam, para assim (re) pensar a sua atuação:

São vários fatores problemáticos em relação a nossa profissão: nós não temos um piso salarial, não temos uma política que nos protege como trabalhadores, nós não temos, nós damos nosso sangue para trabalhar, muitas das minhas coisas, dos meus estudos, sou eu mesma que custeio, eu sou profissional que eu sou hoje porque uma parte do pouco que eu ganho é aplicado nos meus estudos, meu Conselho [Regional de Psicologia] não me ajuda do jeito que eu acho que ele deveria, então hoje em dia eu estou mais tranquila, mais os conflitos eles permanecem, e acho que eles são até saudáveis, se a gente souber levar para uma reflexão crítica (PC3).

Mais uma vez temos a presença de um conflito claro: é muito gratificante trabalhar na área de formação (fazer valer o esforço - e às vezes, o dinheiro gasto na graduação), entretanto, nem tudo é um mar de rosas na profissão. Alguns dos entrevistados deixam esse conflito ainda mais claro quando relatam que já pensaram em abandonar a profissão de psicólogo e se dedicar a outra atividade, mas as pequenas recompensas do dia a dia profissional, os avanços que conseguem junto aos usuários, faz com que os profissionais repensem a sua decisão e insistam em serem psicólogos. 


\subsection{Legislação versus realidade do serviço}

Os psicólogos entrevistados relatam um hiato entre o que prescrevem as legislações ${ }^{4}$ em saúde mental no Brasil e a realidade dos serviços da Rede de Atenção Psicossocial. Esse hiato se expande em duas direções: 1) as condições ofertadas pela Gestão (municipal, estadual e federal) não são suficientes para garantir a assistência em saúde mental conforme as prerrogativas existentes; 2) os profissionais (psicólogos ou não) não conhecem ou não conseguem colocar em prática a legislação vigente em saúde mental.

Quanto à primeira das situações, os profissionais entrevistados relatam vários tipos de dificuldades que impedem o funcionamento pleno do serviço, vejamos os trechos a seguir:

Então, sim, têm muitas dificuldades, algumas coisas são complicadas mesmo, a gente passa alguns nervosos em alguns momentos assim, por não ter a equipe toda, por não ter a parte administrativa, de recepção (PC2). [...] a saúde mental é um construir no dia a dia, o tempo todo, por mais que esteja lá na Portaria, por mais que esteja lá na nossa ciência, o aqui e agora, o fazer, eu digo para você: é só deus que nos ajuda, a nossa persistência, a nossa dedicação, os nossos estudos, o primar pela excelência ética em primeiro lugar, e isso muitas vezes faz você confrontar com gestão (PC3).

Novamente aqui encontramos uma fonte de frustração para os psicólogos: o desejo de colocar em prática a sua "saúde mental ideal" e não conseguir. Os motivos pelos quais eles não alcançam esse ideal são vários, mas podemos notar que ainda assim, os profissionais lutam e tentam driblar as adversidades, e se não conseguem fazer o ideal, tentam fazer, pelo menos, o melhor possível.

As dificuldades em equiparar a oferta dos serviços às condições especificadas pela legislação podem advir também da conduta dos profissionais (nesse caso, não apenas psicólogos) que não tem identificação com as diretrizes da Lei $n^{0} 10.216$ (Brasil, 2001) e suas bases desinstitucionalizantes, e por isso atuam de forma distinta a ela:

[...] se a gente não observar isso todo dia, e tentar romper com isso todo dia, a hora que você percebe você está fazendo uma repercussão de "vem aqui, vamos fazer bordadinho e tchau" sem que isso tenha um gancho com a realidade daquela pessoa, com a realidade social da nossa cidade, com o atendimento do transtorno mental dela, [...] acho que caberia sim a gente de lembrar mais do que realmente preconiza as políticas

\footnotetext{
4 Não iremos pormenorizar as demandas da legislação em saúde mental nesse artigo, pois nosso foco é a experiência dos profissionais. Entretanto cabe esclarecer que estamos considerando como "legislações em saúde mental no Brasil” todos os documentos ofertados pelo Ministério da Saúde para regulação da Atenção Psicossocial como a Lei 10.216 (2001), Portaria 3.088 de 2011, Portaria $n^{\circ} 336 / \mathrm{GM}$ de 2002 , Portaria SAS/MS n 224 de 1992, entre outros.
}

de saúde mental hoje, o que é um CAPS, falta isso, falta estudar, mesmo para você criticar sua própria prática (PC5).

Nunca me imaginei em Saúde Pública, aí comecei a fazer atendimento lá, [...] Ai eu comecei a ver aquele povo pobre, mal tratado, o povo atendia muito mal as pessoas, desde a recepção (PC4).

As transformações na legislação em saúde mental no Brasil nas últimas décadas parecem não ter sido assimiladas por todos os profissionais da mesma maneira, o que leva alguns a terem uma posição crítica em relação à conduta dos seus colegas. Esse dado nos faz refletir sobre como uma mudança na legislação, ou mesmo nas diretrizes de um serviço, não faz com que as alterações ocorram de forma automática no cotidiano desse serviço, e essas novas formas de ação acabam coexistindo com as antigas.

\subsection{Vida profissional versus vida pessoal}

Para os psicólogos entrevistados, trabalhar com saúde mental no Sistema Único de Saúde ultrapassa (e muito) a carga horária que eles devem desempenhar no serviço e se estende para vários aspectos do cotidiano desses profissionais, tendo várias repercussões na vida pessoal, como podemos ver nos relatos abaixo:

Hoje em dia eu me sinto mais em paz comigo mesmo, mas eu muitas vezes pensei em abandonar, jogar a toalha mesmo, [...] eu levava serviço para casa, trabalhava sábado, domingo, feriado, à noite, pensando, preocupada com o usuário, porque a gente sabe de cada usuário nosso (PC3).

Vou ser bem sincera, quando eu assumi aqui, eu estava num pique que eu achei que ia pirar, porque quando eu pego as coisas para mim eu sou determinada, eu quero fazer, eu já quero resolver, quero que tudo ande, eu não estava conseguindo dormir, eu estou tomando ansiolítico até agora, para conseguir dar uma baixada, e tudo pelo trabalho. O meu marido me cobra assim "calma, teu trabalho não é tudo", e ele fica me cobrando porque eu vivo isso aqui, eu entro aqui, eu respiro, e vivo isso aqui 24 horas, eu vou para casa, mas a minha cabeça está aqui (PC4).

Olhando para esses trechos, é notável a oposição que se cria entre a vida familiar e a vida profissional. As atividades a serem desenvolvidas no serviço são muitas ${ }^{5}$ e os profissionais ficam sobrecarregados, assim, os psicólogos entrevistados parecem não ter tempo suficiente para dedicar a todas as suas tarefas da maneira como eles gostariam, e então, ao optar para o que dedicar as suas horas, optam pela vida profissional o que os deixa - e também

\footnotetext{
5 A descrição detalhada dessas atividades está em Muhl (2015).
} 
aos seus familiares - descontentes. Um exemplo dessa invasão da vida profissional na vida familiar nos foi contada por um dos entrevistados que após o seu horário de expediente foi chamado de volta ao serviço para lidar com um internamento.

Segundo os relatos dos profissionais durante as entrevistas podemos elencar alguns dos motivos que levam a sobrecarga de trabalho como: falta de estrutura dos serviços, falta de profissionais, excesso de demanda de atendimentos e cargo de chefia. Entretanto, precisamos destacar que além dos fatores externos há também outro fator importante nessa equação que é a própria pressão que os psicólogos colocam sobre si mesmos, exigindo-se ao máximo nessa experiência de atuar em saúde mental.

Com essa invasão da vida profissional no âmbito que deveria ser da vida pessoal, tensões são geradas, e isso prejudica a saúde mental dos próprios psicólogos como podemos perceber no relato do profissional que passou a fazer uso de medicamentos em decorrência das cobranças em relação ao seu trabalho. Poderíamos dizer então que não existe mais separação entre vida pessoal e vida profissional, esses aspectos se misturam e geram insatisfação nos psicólogos que consideram que não conseguem lidar bem com nenhum dos aspectos: estão em casa preocupados com o serviço e com o usuário, como também devem estar no serviço preocupados com a sua família e sua casa.

\section{Algumas considerações sobre ser-psicólogo na saúde mental}

- Logo se vê - respondeu Dom Quixote que não és versado em coisas de aventuras: são gigantes, sim; e se tens medo aparta-te daqui, e põe-te a rezar no espaço em que vou com eles me bater em fera e desigual batalha.

Miguel de Cervantes

Ser-psicólogo na Rede de Atenção Psicossocial é uma experiência conflituosa, essa é a significação atribuída pelos psicólogos às suas vivências e esse é o principal achado desse estudo. Esse fato pôde ser observado durante as entrevistas, tanto nas falas e nos relatos do cotidiano como nos momentos em que os psicólogos foram dos risos as lágrimas ao nos relatarem as suas experiências dentro dos serviços.

Com o nosso estudo, demonstramos como o fluxo das vivências dos psicólogos que atuam em saúde mental se dá basicamente por experiências contraditórias. Essa experiência ocorre dessa maneira porque esses profissionais se encontram no centro de vários conflitos: a vida profissional que se torna incompatível com a vida pessoal, as situações que trazem satisfação são contrabalanceadas com as situações que frustram, o que a legislação manda e o que a realidade local permite, o que o usuário quer, o que o familiar quer, o que o gestor quer, o que o profissional quer, e o que é possível fazer.

Diante da situação apresentada, poderíamos nos perguntar então: o que motiva esses profissionais a continuarem trabalhando? E encontramos profissionais muito motivados na RAPS. Não nos parece ser a recompensa financeira do salário no final do mês, mas sim o reconhecimento pelo trabalho desempenhado, reconhecimento que vem dos gestores, dos usuários, dos familiares e dos próprios profissionais, que enfrentam gigantes - ou moinhos de vento - todos os dias, e que ao chegarem em casa colocam a cabeça no travesseiro com o sentimento de dever cumprido, ainda que não consigam dormir diante da multiplicidade de incertezas que encontram no seu fazer.

De uma maneira geral, podemos perceber que a atuação no serviço fica aquém do que os psicólogos gostariam - ou desejavam, ou fantasiavam como realidade ou idealidade -, por conta de todos esses conflitos já explicitados. Entretanto, podemos observar que eles empregam todos os seus esforços para fazer esse "pouco" que conseguem e que esse "pouco", na avaliação deles, já produz grandes mudanças na atenção à saúde mental (e na vida das pessoas com transtornos mentais) que, na maioria desses municípios, não existia antes da implementação dos Centros de Atenção Psicossocial.

Os profissionais se encontram sobrecarregados nos seus fazeres no litoral paranaense, haja vista que a vida profissional extravasa e toma conta também da vida pessoal desses profissionais, e essa situação toma contornos de uma situação-limite, avaliada como difícil pelos profissionais como podemos observar nos seus depoimentos, mas não de todo ruim, já que esses profissionais também encontram satisfação no seu cotidiano profissional. Esse é o quadro que encontramos nos serviços de saúde mental da $1^{\text {a }}$ Regional de Saúde do Paraná, mas que pode ser um retrato de uma situação maior, enfrentada por outros profissionais e em outros locais do país no cuidado com as pessoas com transtornos mentais.

No fluxo da vivência desses profissionais, as situações positivas e as situações negativas vão se alternando, conforme as dualidades que elencamos. Nesse momento evocamos novamente a metáfora da moeda, que parece ser a que melhor desenha a situação: o ser-moeda contém a cara e a coroa e o ser-psicólogo da saúde mental pública no litoral paranaense contêm o seu ônus e o seu bônus, esta parece ser a principal característica dessa vivência.

\section{Referências}

Amaral, M. N. P. C. (2004). Dilthey - conceito de vivência e os limites da compreensão nas ciências do espírito. Trans/ Form/Ação, 27, 51-73.

Andrade, C. \& Holanda, A. F. (2010) Apontamentos sobre a pesquisa qualitativa e pesquisa empírico-fenomenológica. Estudos de Psicologia, (27)2, 259-268. 
Brasil. (2001). Lei no 10216 de 06 de abril de 2001 (Dispõe sobre a proteção e os direitos das pessoas portadoras de transtornos mentais e redireciona o modelo assistencial em saúde mental). Brasília: Presidência da República. Disponível em http://www.planalto.gov.br/ccivil_03/leis/leis_2001/ l10216.htm.

Dilthey, W. (2008). Ideias acerca de uma Psicologia Descritiva e Analítica. Corvilhã: Universidade da Beira Interior (Trabalho original publicado em 1894).

Dilthey, W. (2010). A construção do mundo histórico nas ciências humanas. São Paulo: Unesp. (Trabalho original publicado em 1970).

Gomes, W. B. (1997). A Entrevista Fenomenológica e o Estudo da Experiência Consciente. Psicologia USP, 8(2), 305-336.

Holanda, A.F. (2003). Fundamentação Fenomenológica da Pesquisa do Vivido, In: I.I. Costa, A.F. Holanda, F. Martins \& M.I. Tafuri (Orgs.). Ética, Linguagem e Sofrimento (p. 171-183). Brasília: Abrafip.

Holanda, A.F. (2014). Fenomenologia e Humanismo. Reflexões Necessárias. Curitiba: Editoria Juruá.

Husserl, E. (2006). Idéias para uma fenomenologia pura e para uma filosofia fenomenológica: introdução geral à fenomenologia pura. Aparecida, SP: Idéias\& Letras. (Trabalho original publicado em 1913).

Kelkel, A. L. \& Schérer, R. (1954). Husserl. Lisboa: Edições 70.

Ministério da Saúde (2011). Portaria no 3.088 de 23 de dezembro de 2011 (Institui a Rede de Atenção Psicossocial para pessoas com sofrimento ou transtorno mental e com necessidades decorrentes do uso de crack, álcool e outras drogas, no âmbito do Sistema Único de Saúde). Brasília: Ministério da Saúde. Disponível em http://bvsms.saude.gov.br/bvs/saudelegis/gm/2011/prt3088_23_12_2011_rep.html.

Muhl, C. (2015). A atuação do psicólogo na Rede de Atenção Psicossocial: um estudo fenomenológico na Regional de Saúde do litoral do Paraná. (Dissertação de Mestrado) - Programa de Pós-Graduação em Psicologia, Universidade Federal do Paraná.

Ortega y Gasset, J. (2011). Sobre o conceito de sensação. Revista da Abordagem Gestáltica, 17(2), 217-223. (Trabalho original publicado em 1913).

Peres, S. P. (2014). Husserl e o projeto de psicologia descritiva e analítica em Dilthey. Memorandum, 27, 12-28.
Camila Muhl - Psicóloga formada pela Universidade do Oeste de Santa Catarina (UNOESC), Mestra em Psicologia pela Universidade Federal do Paraná e Doutoranda em Sociologia da Universidade Federal do Paraná (PGSOCIO/UFPR). Integrante dos Grupos de Pesquisa: Sociologia da Saúde - UFPR/CNPq e Laboratório de Fenomenologia e Subjetividade - UFPR/CNPq. Endereço Institucional: Praça Santos Andrade, $\mathrm{n}^{0}$ 50, Sala 102, CEP: 80.060-240. Curitiba - PR - Brasil. Email: came.muhl@gmail.com

Adriano Furtado Holanda - Psicólogo, Doutor em Psicologia, Docente do Curso de Psicologia e do Programa de Mestrado em Psicologia na Universidade Federal do Paraná (UFPR), Coordenador do Laboratório de Fenomenologia e Subjetividade (LabFeno-UFPR) e Coordenador do Grupo de Trabalho Psicologia \& Fenomenologia na Anpep. Email: aholanda@yahoo.com / Site: labfenoufpr.com.br

Recebido em 23.09.2015 Primeira Decisão Editorial em 03.03.2016 Aceito em 07.04.2016 